\title{
Pengaruh Relationship Marketing Terhadap Loyalitas Pelanggan Pada Konsumen Tropicana Slim di Kota Padang
}

\author{
Siska Lusia Putri* \\ Lili Nursinta* \\ *)Program Studi Manajemen Fakultas Ekonomi dan Bisnis Universitas Dharma Andalas \\ (UNIDHA) Padang \\ Email:siskalusiaputri@gmail.com
}

\begin{abstract}
Abstrak
Penelitian ini bertujuan untuk menganalisis pengaruh relationship marketing terhadap loyalitas pelanggan dan untuk menentukan variabel dari relationship marketing yang paling dominan berpengaruh terhadap loyalitas pelanggan. Indikator relationship marketing yang digunakan mencakup (kepercayaan, komitmen, dan komunikasi) pada konsumen Tropicana Slim di Kota Padang. Metode penelitian yang digunakan adalah deskriptif kuantitatif dengan menggunakan analisis regresi dan korelasi. Hasil penelitian menunjukkan bahwa semua indikator relationship marketing (kepercayaan, komitmen, dan komunikasi) bernilai positif dan berpengaruh terhadap loyalitas pelanggan dan nilai R-Square untuk semua indikator bernilai 0.650 .
\end{abstract}

Kata kunci : relationship marketing, loyalitas pelanggan, tropicana slim

\begin{abstract}
The aim of this study was to determine the influences of relationship marketing to customer loyalty and to determine the variables of the most dominants of marketing relationship influence on customer loyalty. Relationship marketing indicators that studied were belief, commitment, and communication in customer of Tropicana Slim in Padang city. This research was descriptive quantitative attribute that described the influence of consumer relationship marketing Tropicana Slim using regression analysis and correlation. The study design used was cross sectional with a single method of sampling non probability sampling. The results of this study indicated that the indicators of relationship marketing included belief, commitment, and communication positive and significant impact on consumer loyalty. The indicators of relationship marketing (belief, commitment, and communication) were simultaneously positive and significant impact on consumer loyalty. The value of adjusted $R$ Square indicators was 0.650 .
\end{abstract}

Keywords: relationship marketing, consumer loyalty, tropicana slim

\section{PENDAHULUAN}

\begin{tabular}{lr}
\multicolumn{2}{r}{ Relationship marketing adalah } \\
proses berkelanjutan & yang \\
mensyaratkan suatu perusahaan agar \\
menjalin komunikasi tetap dengan \\
konsumen untuk memastikan tujuan \\
tercapai, dan memadukan proses
\end{tabular}

relationship marketing ke dalam rencana strategi sehingga memungkinkan perusahaan mengelola sumber daya dengan baik dan memenuhi kebutuhan konsumen di masa mendatang. Hubungan yang hangat bisa mencairkan kebekuan. Hubungan itu harus 
didasarkan oleh prinsip-prinsip ketulusan dan saling mendukung, bukan sekedar hubungan transaksional yang semu dan semata-mata karena perintah kerja atau hanya untuk mencari keuntungan semata. Bila pemasar berdiri dipihak pelanggan dan memandang masalah yang dihadapi pelanggan juga sebagai masalahnya lalu berusaha memecahkan secara bersamasama, maka hubungan jangka panjang ini akan dirasakan oleh kedua belah pihak.

Loyalitas merupakan respon perilaku, diekspresikan dalam jangka waktu yang panjang, dan menghasilkan komitmen. Loyalitas dapat memberikan jaminan masa depan perusahaan yang lebih baik. Hubungan yang dekat dan berlangsung lama dengan para konsumen biasanya menunjukan adanya pengurangan biaya layanan, dikarenakan pengetahuan perusahaan mengenai kebutuhan-kebutuhan pelanggan semakin bertambah, sehingga perusahaan pada akhirnya mampu untuk menyediakan layanan yang lebih baik pada biaya yang lebih rendah. Pelanggan yang loyal merupakan aset terbesar bagi sebuah perusahaan. Hal ini karena pelanggan tersebut dapat berkomunikasi melalui kata dari mulut ke mulut yang menguntungkan tentang perusahaan atau produk yang digunakan sehingga dapat menarik pelanggan baru bagi perusahaan. Hal tersebut kemudian berdampak pada manfaat yang diperoleh dari penjualan, pendapatan dan laba perusahaan (Kotler, 2006).

Beberapa dekade terakhir, kesadaran masyarakat dunia akan pentingnya menjaga kesehatan semakin meningkat. Peningkatan ini adanya kekhawatiran masyarakat tentang tingginya angka kematian beberapa tahun terakhir ini, bukan hanya kesehatan tetapi juga kelangsungan hidup umat manusia. Terbentuknya kesadaran konsumen mengenai haknya untuk mendapatkan produk yang layak, aman, dan ramah lingkungan semakin kuat, sehubungan dengan hal tersebut perusahaan berusaha menciptakan produk untuk kesehatan konsumen salah satunya produk Tropicana Slim.

Tropicana Slim adalah nama merek produk dagang asli Indonesia yang dimiliki oleh perusahaan Nutrifood Indonesia. Susu dan makanan ini dirilis pada tahun 1978 dan sejak dulu sangat konsisten dikonsentrasikan untuk kontrol dan pencegahan diabetes. Produk yang disediakan sangat beragam mulai dari pemanis rendah kalori, susu, hingga bahan-bahan untuk memasak. Produk susu dan makanan ini juga memiliki nutrisi yang paling lengkap. Tropicana Slim hadir untuk solusi gula rendah kalori. Tidak hanya untuk para penderita diabetes atau orang-orang yang lanjut usia, Tropicana Slim hadir untuk semua orang di semua umur. Produk ini sangat bagus untuk pola hidup sehat. Tropicana Slim dikonsumsi untuk penderita diabetes, mencegah diabetes, selain itu untuk mengontrol asupan kalori agar badan tetap ideal dan ramping. Data yang tergambar dalam Tabel 1 di bawah ini mencakup jumlah pelanggan yang menggunakan produk Tropicana Slim di Kota Padang pada Tahun 2016. 
Tabel 1. Jumlah Pelanggan Tropicana Slim di Kota Padang periode JuliDesember 2016

\begin{tabular}{|c|c|c|}
\hline No & Bulan & $\begin{array}{c}\text { Jumlah } \\
\text { Pelanggan }\end{array}$ \\
\hline 1 & Juli & 454 orang \\
\hline 2 & Agustus & 518 orang \\
\hline 3 & September & 548 orang \\
\hline 4 & Oktober & 542 orang \\
\hline 5 & Novemberr & 507 orang \\
\hline 6 & Desember & 483 orang \\
\hline & Jumlah & 3,052 orang \\
\hline & Sumber & Nutrifooc \\
\hline
\end{tabular}

Tropicana Slim masih merupakan produk yang memiliki pangsa pasar terbesar untuk setiap tahunnya. Hal ini menunjukkan adanya konsistensi dan kepercayaan dari pelanggan terhadap produk tersebut. Penjualan Tropicana Slim lebih meningkat dibandingkan dengan produk yang sama dengan merek yang berbeda, dimana Tropicana Slim penjualannya mencapai $79.6 \%$ dibanding Diabetasol yang penjualannya mencapai $14.7 \%$, Equal 2.6\%, dan Diasweet $1.6 \%$ sehingga Tropicana Slim lebih unggul dan menjadi Top Brand yang meraih penjualan tertinggi. Berdasarkan latar belakang di atas, maka rumusan masalah dalam penelitian ini adalah sebagai berikut yaitu bagaimana pengaruh kepercayaan, komitmen, komunikasi terhadap loyalitas pelanggan Tropicana Slim di Kota Padang

\section{METODE PENELITIAN}

Penelitian dilakukan di Kota Padang, Propinsi Sumatera Barat. Penelitian dilakukan selama enam bulan, dimulai pada bulan Oktober 2016 sampai dengan Maret 2017. Jenis data yang digunakan dalam penelitian ini adalah data primer dan data sekunder. Data primer yang digunakan diperoleh melalui diskusi dan wawancara langsung yang dipandu dengan kuesioner. Data sekunder diperoleh dari berbagai sumber kepustakaan yang dianggap relevan.

Metode penarikan sampel yang digunakan dalam penelitian ini adalah dengan menggunakan metode accidental sampling. Accidental sampling adalah teknik penentuan sampel berdasarkan kebetulan, yaitu siapa saja yang secara kebetulan/ insidental bertemu dengan peneliti dapat digunakan sebagai sampel, bila dipandang orang yang kebetulan ditemui itu cocok sebagai sumber data (Sugiyono, 2014).

\section{Teknik Pengolahan dan Analisis Data}

\section{Uji Normalitas}

Uji normalitas data adalah pengujian terhadap normal tidaknya sebaran data yang akan dianalisis Suharsimi (2009).

\section{Uji Multikolinearitas}

Multikolenieritas adalah kolerasi antara variabel independen satu dengan yang lain. "Model regresi yang baik seharusnya tidak terjadi kolerasi diantara variabel independen" (Ghozali, 2006).

\section{Uji Heteroskedastisitas}

Uji heteroskedastisitas bertujuan untuk menguji apakah dalam model regresi terjadi ketidaksamaan variance dari residual satu pengamataan ke pengamatan yang lain tetap, atau disebut homoskedastisitas. 


\section{Analisis Deskriptif}

Analisis deskriptif digunakan dengan menginterpretasikan data-data yang didasarkan fakta-fakta yang tampak dalam kurun waktu yang diselidiki sehingga diperoleh gambaran yang jelas tentang objek yang diteliti (Sugiyono, 2008).

\section{Analisis Regresi Berganda}

Dalam analisis regresi ganda, bentuk umum yang digunakan menurut Sutrisno (2004) adalah dengan rumus:

$$
Y=a_{1} X_{1}+a_{2} X_{2}+a_{3} X_{3}+k
$$

\section{Koefisien Determinasi $\left(R^{2}\right)$}

Uji ketepatan perkiraan $\left(\mathrm{R}^{2}\right)$ dilakukan untuk mendeteksi ketepatan yang paling baik dalam analisis regresi.

\section{Uji Hipotesis}

Uji hipotesis adalah metode pengambilan keputusan yang didasarkan dari analisis data, baik dari percobaan yang terkontrol, maupun dari observasi (tidak terkontrol).

\section{- Uji t}

Menurut Sugiyono (2008), Uji t dilakukan untuk menguji signifikansi konstanta dan setiap variabel independen akan berpengaruh terhadap variabel dependen.

\section{- Uji F}

Setelah diperoleh hasil perhitungan, kemudian $\mathrm{F}$ hitung dikonsultasikan dengan $\mathrm{F}$ tabel pada taraf signifikansi 5\%.

\section{HASIL DAN PEMBAHASAN \\ Karakteristik Responden}

Usia

Responden paling banyak berusia >35 tahun dengan jumlah 57 orang.
Kemudian disusul dengan responden dengan usia 29-34 tahun sebanyak 28 orang. Terakhir, responden dengan usia 23-28 tahun sebanyak 15 orang. Jenis Kelamin

Responden paling banyak dengan jenis kelamin perempuan sebanyak 87 orang. Sedangkan responden laki-laki berjumlah sebanyak 13 orang.

Pendidikan Terakhir

Responden paling banyak berdasarkan pendidikan terakhir adalah SMA dengan jumlah 35 orang. Kemudian disusul dengan responden dengan pendidkan terakhir S1 sebanyak 32 orang. Terakhir, responden dengan pendidikan terakhir D3 sebanyak 28 orang.

Pekerjaan

Responden paling banyak adalah ibu rumah tangga dengan jumlah 40 orang. Kemudian disusul dengan responden dengan pekerjaan PNS sebanyak 35 orang. Terakhir, responden dengan pekerjaan karyawan swasta sebanyak 25 orang.

\section{Uji Instrumen}

Uji Validitas

Hasil penelitian menunjukkan bahwa 13 butir item pernyataan seluruhnya adalah valid, karena corected item total correlation lebih besar dibanding 0.30 seperti yang dijelaskan oleh Sugiyono (2008). Item Angket dapat dijadikan acuan untuk penelitian selanjutnya. Dalam kasus ini berarti semua item yang terdiri dari kepercayaan $\left(\mathrm{X}_{1}\right)$, komitmen $\left(\mathrm{X}_{2}\right)$, komunikasi $\left(\mathrm{X}_{3}\right)$, dan loyalitas konsumen $(\mathrm{Y})$ memenuhi persyaratan validitas secara statistik. 


\section{Uji Reliabilitas}

Hasil penelitian menunjukkan bahwa setiap item yang terdiri dari: kepercayaan $\left(\mathrm{X}_{1}\right)$, komitmen $\left(\mathrm{X}_{2}\right)$, komunikasi $\left(\mathrm{X}_{3}\right)$, dan loyalitas konsumen $(\mathrm{Y})$ menghasilkan nilai alpha cronbath > 0.60, sehingga dapat disimpulkan bahwa seluruh variabel yang didukung oleh item pertanyaan yang valid memiliki tingkat kehandalan yang tinggi dan reliabel (diterima), sehingga dapat digunakan dalam penelitian ini.

\section{Analisis Deskriptif}

Analisis Deskriptif Kepercayaan

Hasil penelitian menunjukkan bahwa pernyataan yang paling dominan yakni responden yang menjawab baik pada Tropicana Slim konsisten dalam menyediakan layanan yang berkualitas. Hal ini dikarenakan nilai tingkat capaian responden $\quad 77.2 \%$. Sedangkan pernyataan yang paling sedikit pada responden yang menjawab baik yaitu pada Tropicana Slim sangat memperhatikan keamanan dalam bertransaksi dengan pelanggan dengan tingkat capaian responden $74.6 \%$.

Analisis Deskriptif Komitmen

Hasil penelitian menunjukkan bahwa pernyataan yang paling dominan yakni responden yang menjawab baik pada Tropicana Slim melakukan penyuluhan kepada pelanggannya agar tidak ada keraguan dan kesalahpahaman terhadap produk yang diberikan. Hal ini dikarenakan nilai tingkat capaian responden $\quad 77.4 \%$. Sedangkan pernyataan yang paling sedikit pada responden menjawab baik yaitu pada Tropicana Slim membuat penyesuaian untuk memenuhi kebutuhan pelanggan dengan tingkat capaian responden $68.4 \%$.

\section{Analisis Deskriptif Komunikasi}

Hasil penelitian menunjukkan bahwa pernyataan yang paling dominan yakni responden yang menjawab sangat baik pada Tropicana Slim memilki kontak yang jelas yang dapat dihubungi oleh pelanggan Hal ini dikarenakan nilai tingkat capaian responden $81 \%$. Sedangkan pernyataan yang paling sedikit pada responsiveness responden menjawab baik yaitu pada Tropicana Slim memberikan informasi yang tepat dan dapat dipercaya dengan tingkat capaian responden $70.8 \%$.

Analisis Deskriptif Loyalitas Konsumen

Hasil penelitian menunjukkan bahwa pernyataan yang paling dominan yakni responden menjawab baik pada saya tetap menggunakan produk Tropicana Slim untuk setiap kebutuhan. Hal ini dikarenakan nilai tingkat capaian responden $\quad 78.8 \%$. Sedangkan pernyataan yang paling sedikit yakni responden menjawab baik yaitu saya tetap menggunakan produk Tropicana Slim walaupun banyak produk sejenis lainnya dan saya selalu membicarakan hal-hal yang positif tentang produk Tropicana Slim dengan tingkat capaian responden $74.4 \%$.

\section{Uji Asumsi Klasik \\ Uji Normalitas}

Dalam penelitian ini uji normalitas dapat dilihat pada Gambar 1 . berikut ini. 
Normal P-P Plot of Regression Standardized Residual

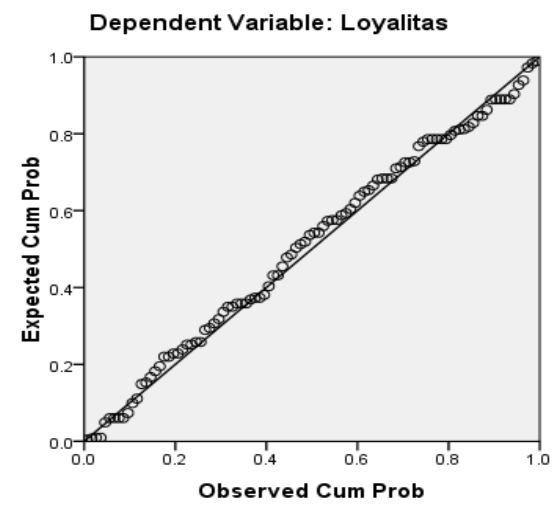

\section{Gambar 1. Uji Normalitas}

Dari Gambar 1. terlihat bahwa data menyebar di sekitar diagram dan mengikuti model regresi sehingga dapat disimpulkan bahwa data yang diolah merupakan data yang berdistribusi normal sehingga uji normalitas terpenuhi.

\section{Uji Multikolinearitas}

Uji multikolinearitas bertujuan untuk melihat ada atau tidaknya korelasi yang tinggi antara variabelvariabel bebas dalam suatu model regresi linear berganda. Jika ada korelasi yang tinggi diantara variabel-variabel bebasnya, maka hubungan antara variabel bebas terhadap variabel terikatnya menjadi terganggu (Kurniawan, 2014).

Tabel 2 uji Multikolinearitas yang diperoleh di lapangan.

\begin{tabular}{|c|c|c|c|c|c|c|c|}
\hline \multicolumn{8}{|c|}{ Coefficients $^{a}$} \\
\hline \multirow[b]{2}{*}{ Model } & \multicolumn{2}{|c|}{$\begin{array}{l}\text { Unstandardized } \\
\text { Coefficients }\end{array}$} & \multirow{2}{*}{$\begin{array}{c}\text { Standardize } \\
\mathrm{d} \\
\text { Coefficients } \\
\text { Beta }\end{array}$} & \multirow[b]{2}{*}{$\mathrm{t}$} & \multirow[b]{2}{*}{ Sig. } & \multicolumn{2}{|c|}{$\begin{array}{l}\text { Collinearity } \\
\text { Statistics }\end{array}$} \\
\hline & B & Std. Error & & & & $\begin{array}{c}\text { Toleran } \\
\text { ce }\end{array}$ & VIF \\
\hline 1 (Constant) & .047 & .294 & & .159 & .874 & & \\
\hline Kepercayaan & .214 & .065 & .211 & $\begin{array}{r}3.28 \\
3\end{array}$ & .001 & .853 & 1.172 \\
\hline Komitmen & .449 & .062 & .492 & $\begin{array}{r}7.27 \\
6\end{array}$ & .000 & .774 & 1.292 \\
\hline Komunikasi & .346 & .072 & .346 & $\begin{array}{r}4.80 \\
3\end{array}$ & .000 & .683 & 1.465 \\
\hline
\end{tabular}

Sumber: Olahan SPSS, 2017

Dari Tabel 2. di atas diperoleh bahwa semua nilai $\mathrm{VIF}<10$ dan semua nilai tolerance $>0.10 \%$, ini berarti tidak terjadi multikolonieritas. Maka kesimpulannya bahwa uji Asumsi Klasik terpenuhi.
Uji Heteroskedastisitas

Uji Heteroskedastisitas adalah untuk melihat apakah terdapat ketidaksamaan varians dari residual satu ke pengamatan ke pengamatan yang lain. Model regresi yang memenuhi persyaratan adalah dimana terdapat 
kesamaan varians dari residual satu pengamatan ke pengamatan yang lain tetap atau disebut homoskedastisitas
(Kurniawan, 2014). Gambar 2. berikut merupakan hasil olahan data uji heteroskedastisitas.

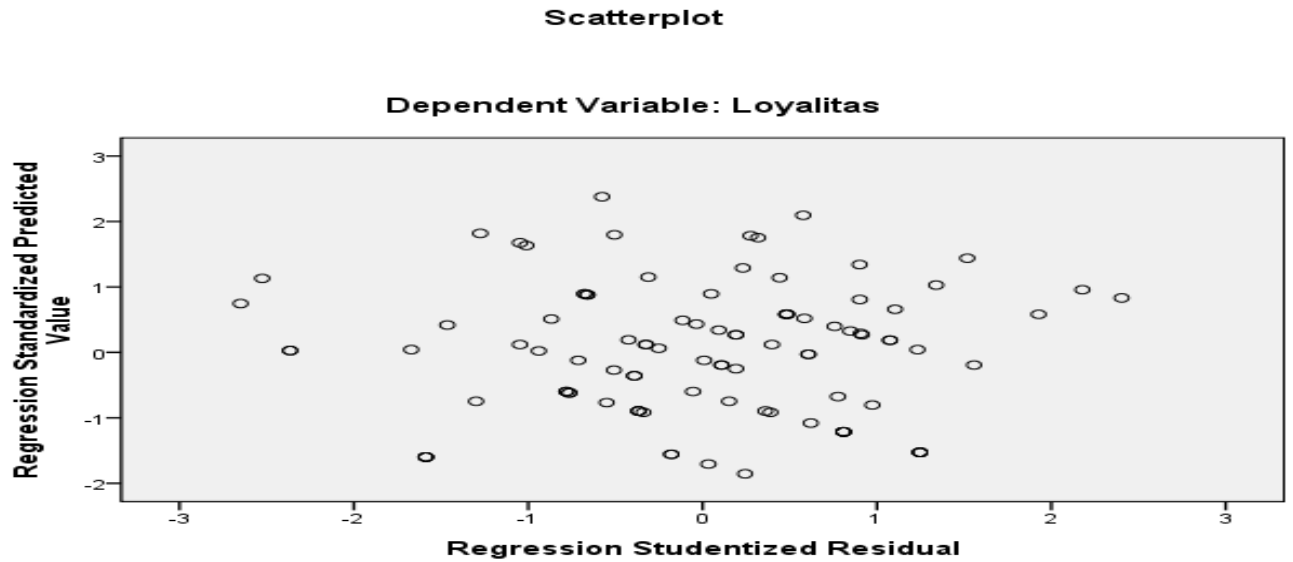

Gambar 2. Uji Heteroskedastisitas

Dari Gambar 2. di atas dapat diketahui bahwa tidak terjadi heteroskedastisitas sebab tidak ada pola yang jelas serta titik-titik menyebar di atas dan di bawah angka 0 pada sumbu Y, sehingga dapat dikatakan uji Asumsi Klasik terpenuhi.

\section{Analisis Regresi Linier Berganda}

Dari Tabel 3 di bawah dapat digambarkan persamaan regresi linear berganda sebagai berikut :

$$
\mathrm{Y}=0.047+0.214 \mathrm{X} 1+0.449
$$

$\mathrm{X} 2+0.346 \mathrm{X} 3+\mathrm{e}$

Tabel 3. Hasil Analisis Regresi Linier Berganda

Coefficients $^{\mathrm{a}}$

\begin{tabular}{|c|c|c|c|c|c|c|c|c|}
\hline & \multirow[b]{2}{*}{ Model } & \multicolumn{2}{|c|}{$\begin{array}{l}\text { Unstandardized } \\
\text { Coefficients }\end{array}$} & \multirow{2}{*}{$\begin{array}{c}\text { Standardized } \\
\text { Coefficients } \\
\text { Beta }\end{array}$} & \multirow[b]{2}{*}{$\mathrm{T}$} & \multirow[b]{2}{*}{ Sig. } & \multicolumn{2}{|c|}{$\begin{array}{c}\text { Collinearity } \\
\text { Statistics }\end{array}$} \\
\hline & & B & Std. Error & & & & $\begin{array}{c}\text { Toleran } \\
\text { ce }\end{array}$ & VIF \\
\hline \multirow[t]{4}{*}{1} & (Constant) & .047 & .294 & & .159 & .874 & & \\
\hline & Kepercayaan & 214 & .065 & .211 & $\begin{array}{r}3.28 \\
3\end{array}$ & .001 & .853 & 1.172 \\
\hline & Komitmen & .449 & .062 & .492 & $\begin{array}{r}7.27 \\
6\end{array}$ & .000 & .774 & 1.292 \\
\hline & Komunikasi & .346 & .072 & .346 & $\begin{array}{r}4.80 \\
3\end{array}$ & .000 & .683 & 1.465 \\
\hline
\end{tabular}

Sumber: Olahan SPSS, 2017

Dari persamaan tersebut dapat dijelaskan bahwa:
1. Nilai Constan bernilai positif artinya tanpa adanya variabel 
bebas nilai constant tetap sebesar 0.047 .

2. Variabel Kepercayaan bernilai positif sebesar 0.241, hal ini berarti jika variabel kepercayaan naik satu-satuan maka akan meningkatkan loyalitas pelanggan sebesar 0.241. Dengan asumsi variabel komitmen dan komunikasi tetap.

3. Variabel Komitmen bernilai positif sebesar 0.449 , hal ini berarti jika variabel komitmen naik satu-satuan maka akan meningkatkan loyalitas pelanggan sebesar 0.449. Dengan asumsi variabel kepercayaan dan komunikasi tetap.

4. Variabel Komunikasi bernilai positif sebesar 0.346, hal ini berarti jika variabel komunikasi naik satu-satuan maka akan meningkatkan loyalitas pelanggan sebesar 0.346. Dengan asumsi variabel kepercayaan dan komitmen tetap.

\section{Uji Hipotesis}

Uji Parsial (Uji t)

Hasil penelitian menunjukkan bahwa secara parsial variabel kepercayaan berpengaruh positif dan signifikan terhadap loyalitas pelanggan, hal ini dikarenakan nilai signifikansi $<0.05$ $(0.000>0.05)$ maka ho ditolak dan ha diterima. Variabel komitmen berpengaruh positif dan signifikan terhadap loyalitas pelanggan, hal ini dikarenakan nilai signifikansi $<0.05$ $(0.000>0.05)$. Variabel komunikasi berpengaruh positif dan signifikan terhadap loyalitas pelanggan, hal ini dikarenakan nilai signifikansi $<0.05$ $(0.000>0.05)$.

\section{Uji F (Uji Simultan)}

Hasil penelitian menunjukkan bahwa nilai $F$ hitung sebesar 62.324 dengan taraf signifikansi $0.000<0.05$ sehingga Ho ditolak dan Ha diterima. Dengan demikian dapat disimpulkan bahwa, secara simultan / bersama-sama relationship marketing yang terdiri dari kepercayaan, komitmen, dan komunikasi berpengaruh positif dan signifikan terhadap loyalitas pelanggan.

\section{Uji Koefisien Determinasi $\left(R^{2}\right)$}

Hasil penelitian menunjukkan bahwa nilai koefisien korelasi linear adalah 0.813 , artinya menunjukkan hubungan yang kuat antara variabel independen, yaitu relationship marketing yang terdiri dari kepercayaan, komitmen, dan komunikasi terhadap loyalitas pelanggan, dan juga menjelaskan bahwa nilai koefisien determinasi linear berganda (Adjusted R-Square) mempunyai nilai 0.650 atau $65 \%$. Sedangkan sisanya $35 \%$ merupakan hubungan dengan variabel lainnya diluar penelitian ini.

\section{PEMBAHASAN}

Dari hasil yang telah diolah dengan menggunakan SPSS versi 21 maka dapat jelaskan pembahasannya adalah sebagai berikut :

Tabel 4. Kualitas Pelayanan terhadap Kepuasan Pelanggan

\begin{tabular}{clcl}
\hline No & \multicolumn{1}{c}{ Variabel } & Hipotesis & Ket. \\
\hline 1. & Kepercayaan & Diterima & Sig. \\
2. & Komitmen & Diterima & Sig. \\
3. & Komunikasi & Diterima & Sig. \\
4. & Loyalitas & Diterima & Sig. \\
& Pelanggan & & \\
\hline
\end{tabular}

Sumber: Data Primer, 2017 


\section{SIMPULAN}

SPSS. Semarang: Badan Penerbit

Berdasarkan penelitian yang Universitas Diponegoro.

telah dilakukan, maka dapat ditarik kesimpulan bahwa variabel relationship marketing yang terdiri dari kepercayaan, komitmen, dan komunikasi berpengaruh terhadap loyalitas pelanggan. Hal ini disebabkan karena adanya kesadaran dini dari pelanggan Tropicana Slim terhadap besarnya manfaat yang diperoleh dengan mengkonsumsi produk tersebut. Selain itu, program-program rutin yang diselenggarakan oleh PT. Nutrifood Indonesia seperti Hands 4 Diabetes, Blogger Gathering, Campaign Smart E dan Senam Sehat Tropicana Slim sangat membantu pelanggan untuk memberikan edukasi supaya selalu hidup sehat dan aktif.

\section{DAFTAR PUSTAKA}

Ghozali, Imam. 2006. Aplikasi Analisis Multivariate dengan Program

Kotler, P., Keller Kevin Lane. 2006. Marketing Management. (12e) New York:McGraw-Hill.

Kurniawan, Albert. 2014. Metode Riset untuk Ekonomi dan Bisnis Teori, Konsep, dan Praktik Penelitian Bisnis (Dilengkapi Perhitungan Pengolahan data dengan IBM SPSS 22,0). Bandung: Alfabeta CV.

Sugiyono. 2008. Metode Penelitian Kuantitatif, Kualitatif dan $R \& D$. Bandung: Alfabeta.

Sugiyono. 2014. Metode Penelitian Bisnis. Bandung: Alfabeta.

Suharsimi, Arikunto. 2009. Manajemen Penelitian. Jakarta: Rineka Cipta.

Sutrisno, Hadi. 2004. Analisis Regresi. Yogyakarta: Andi Offset. 